\title{
Creative Problem-Solving (CPS) Skills among University Students
}

\author{
Muhammad Syawal Amran, Faridah Mydin Kutty, Shahlan Surat \\ Centre for Teaching \& Learning Innovation, University Kebangsaan Malaysia, Bangi, Malaysia \\ Email: syawal@ukm.edu.my
}

How to cite this paper: Amran, M. S., Kutty, F. M., \& Surat, S. (2019). Creative Problem-Solving (CPS) Skills among University Students. Creative Education, 10, 3049-3058.

https://doi.org/10.4236/ce.2019.1012229

Received: October 18, 2019

Accepted: November 26, 2019

Published: November 29, 2019

Copyright (c) 2019 by author(s) and Scientific Research Publishing Inc. This work is licensed under the Creative Commons Attribution International License (CC BY 4.0).

http://creativecommons.org/licenses/by/4.0/

(c) (i) Open Access

\begin{abstract}
Malaysia had launched the National Education Blueprint (Higher Education) 2015-2025 aimed to improve higher education. There are six learner's aspirations that have been identified to promote excellence in higher education. The blueprint aimed to develop the attributes of students and graduates in line with the world of $21^{\text {st }}$ century education. One of the attributes that have been emphasized is Creative Problem-Solving (CPS) skills. CPS skills refer to the ability of individuals to solve problems through the development of creative and brilliant ideas. Thus, this paper will present the concept of creative problem-solving skills among university students. Furthermore, this paper will describe the issues and challenges in creative problem solving and the factors that influence this skill. Additionally, a review of creative problem solving (CPS) skills theory is proposed to understand the information processing in order to approach the problem creatively among students and university lecturers. Therefore, this paper will provide inputs to empowering students and higher institution for creative problem-solving skills.
\end{abstract}

\section{Keywords}

Creative Problem Solving Skills (CPS), University Students

\section{Introduction}

Malaysia is committed to being a developed and competitive country while undertaking the pressure and vast challenges in $21^{\text {st }}$ century. Rapid changes in the educational environment that is suitable for this century demand a progressive and dynamic system towards educational attainment in line with global challenges. Realizing this, the Ministry of Education has launched the National Education Blueprint (Higher Education) 2015-2025 to enhance the national education system. These changes have contributed to the transformation of the higher 
education setting, especially in empowering universities and graduates. This is because, university does not only function as the center of excellence in knowledge, yet university needs to enhance its role in producing the talented individuals that can cater all the current and future needs of this nation (Ruhizan Yasin \& Shairah, 2014; Saeidah \& Nooreen, 2013). This is in line with the National Education Philosophy that proposed to develop the full potential of individuals in terms of physicals, emotions, spirituals and intellects.

In empowering students in the $21^{\text {st }}$ century, there are six learner's aspirations that have been identified as catalysts in driving the nation's higher education excellence. Among the indications of the plan was developing student attributes that fit into the $21^{\text {st }}$ century education approach. One of the attributes that are emphasized is the ability to think creatively in problem solving. This is because creativity enables students to solve problems and explore new ideas parallel with the desire of a nation that wants to produce students with innovative minds.

Creative problem-solving skill is a skill that students need in addition to the academic field to be more successful and excellent (Hu et al., 2017; Leisian Sa \& Tatiana, 2015). Besides that, creative problem-solving skills refer to individuals' ability to solve problems by generating thoughtful and creative ideas (Halizah \& Ishak Ramly, 2008; Saeideh Bolandifar \& Nooren Nordin, 2013). Problem solving requires the ability to utilize the mind for exploring ideas and alternative ways to overcome the shortcomings or barriers in achieving the desired objectives. Nevertheless, few people know the concept and implementation of creative solution skills among university students.

Generally, Creative Problem Solving (CPS) is simply considered a creative endeavor in creating something new without having to do with the problem solving aspect. Instead, the process of solving a problem requires creative effort and requires its own process (Barutcu, 2017; Dolgun \& Erdoğan, 2012). Considering the importance of the implementation and process of CPS, this paper will discuss in further the concept of Creative Problem Solving (CPS) in terms of theory, implementation, as well as look at the factors that influence this practice. Furthermore, taking into account the principles, approaches and current needs, this paper introduces a more comprehensive concept of Creative Problem Solving (CPS) across the contexts of lecturers, students as well as intrauniversity and interuniversity.

\section{Creative Problem Solving: Challenges \& Issues}

Creativity is a continuous process that refers to one's ability to process information and produce something new and original. Torrance (1993) creative thinking is the ability for someone to analyze information and re-shape it into a unique idea. Responding to environmental stimuli is a factor in the development of creative thinking that is used as a solution to the problem and thus brings the individual to a better level. People become more creative when they constantly solve daily problems in different ways (Kanbay et al., 2013; Kuo-Hing Tsemg et al., 2013; Mumford et al., 2000). The foundations of creativity include 1) originality, 
2) appropriateness, 3) future orientation and 4) ability to solve problems (Marke et al., 2008; Fernando et al., 2013; David et al., 2013). In this context, creative thinking not only looks at the ability to solve problems but identifies how students find alternatives to solve a problem. These alternatives require the discovery of new ideas and details of knowledge that can build students' ability to overcome an issue.

From the discussion presented above, it is concluded that creativity affects the ability to make decisions, constantly enhances the capability of ideas and oneself as well as increases productivity in dealing with problems (Adams et al., 2009; Abraham et al., 2013; Elaheh \& Barjoyai, 2012). However, the real question is "Do students" knowledge and understanding of problem solving skills use creative strategies that include creative thinking processes?, Carefully and judiciously, limited understanding and knowledge have restricted the search for the right thinking. This is where the role of knowledge and understanding related to creative skills can be adapted to a problem (Sternberg \& Lubart, 2004; Dolgun \& Erdoğan, 2012). Therefore creative thinking can generate countless ideas as well as flexible enough in generating different and new ideas.

Existing challenges and gaps in national education system actually need attention, understanding and collaborative action in further. Creative Problem Solving Skills (CPS), Creativity in education should be given realistic attention. This is conjunction with the more complex demands of life in the $21^{\text {st }}$ century require students to have first-class thinking (Ministry of Education Malaysia, 2012). Execution and implementation of Creative Problem Solving Skills (CPS) can be seen through the enforcement especially in education. In fact, Malaysia's education curriculum and teacher's teaching have less emphasis on thinking processes especially on creative problem solving skills (Alane, 2010; Cheng, 2011; David et al., 2013). Sternberg \& Lubart (2004) stated that understanding of creative thinking skills in problem solving is not well understood and difficult to be taught. This is because the application of creative thinking skills requires deep understanding to be applied in the classroom.

In the higher education context, lecturers play a vital role in motivating students to generate creative thinking especially while teaching and learning process occurred. Teaching pedagogy is not only focusing on transmitting knowledge but also this mechanism can produce better students in learning process and improve their achievement (Sri \& Jailani, 2013; Yu-Shan Chang, 2013). This process will help the students to understand the knowledge and master it well and be able to generate creative thinking in solving an issue. Nonetheless, using a pedagogical approach integrated with teaching creative problem-solving skills can develop students' minds to be more creative.

One aspect that needs to be understood in discussing the Creative Problem Solving (CPS) is environmental factor. According to Sternberg \& Lubart (2004) the level of individuals who are creative in solving a problem cannot be analyzed without taking account the environmental factors. The integration between the problem-solving process and the creativity can be seen through the press ele- 
ments that refer to the environment. The environment or the press can be viewed through the interaction of lecturers and students (Yahaya Buntat \& Noor Sharliana (2011)). Studies conducted on university students showed that environmental factors were factors that have influenced creative problem solving skills (Dolgun \& Erdoğan, 2012; Kanbay et al., 2013). In addition, studies showed that active involvement of students through interactions within and outside of college can generate more critical and creative thinking in problem solving (Zhiqiang et al., 2011; Cheng Kai Wen, 2011). However, the concern is that many of the students are embarrassed or afraid to interact with the lecturer. Batıgün \& Kayış (2014) stated that university students are more prone to listen and comment on what the lecturers have explained, this does not encourage the process of developing creative problem solving skills. Through the interaction of lecturers and teachers, the students will be trained and familiarised themselves with the culture of freedom to express their thoughts and opinions (Leisian Salakhatdinova \& Tatiana Palei, 2015). In fact, this interaction process can foster a more creative culture of problem solving and develop students' current knowledge.

On the other hand, most researchers focus more on the development of creative problem solving skills that involve interaction in formal learning settings but less on informal learning. Torrancce (1993) stated that a person with a broad opportunity to make choices will have a high level of creative thinking. In other words, these opportunities not only occur in the classroom environment but also occur outside of informal learning settings. Indeed, the process of interacting in developing creative writing skills not only contributes to students' cognitive function but also affects student's personality and leadership. Studies showed that individuals with creative solution skills influence leadership and their ability to generate innovative thinking (Al Jughaiman \& Mowrer-Reyolds, 2005; Abraham Carmeli et al., 2013). Therefore, to be successful in developing creative problem solving skills, through interaction both through formal and informal settings can have implications for university students. In short, the response to environmental stimuli is a factor in the formation of creative thinking which is used as a solution to the problem and thus brings the individual to a better level.

Based on the issues proposed, the recommended solution through the Education Blueprint (Higher Education) 2015-2025 should be understood and appreciated by all. This paper will provide input towards the policy of higher education that supports the role of the university at the micro level in developing students' capabilities in the $21^{\text {st }}$ century skills. Therefore, this awareness is very critical as we need to be prepared of the various stages of the educational cycle in producing graduates who are able to generate ideas or something new and competitive.

\section{Creative Problem Solving Skills: Theoretical Perspective}

The concept of Creative Problem Solving (CPS) is not a new skill, but it does 
take into account the role of creativity in solving a problem. This is proven true as there is a link between human thinking and the context of life in which knowledge and skills in solving a problem can be developed and channelled through the application of daily life. In this context, each individual has his or her own skills either real or hidden. Nevertheless, mastery of these skills will open up opportunities for students to acquire new knowledge and skills or to strengthen their existing knowledge. Since the concept of Creative Problem Solving (CPS) is abstract, this theory will be presented to clearly understand the role of creative thinking in problem solving.

The ideas for creative problem solving (CPS) began in 1963 when Osborn proposed seven stages in creativity, 1) problem orientation, 2) preparation, 3) hypothesis, 4) incubation, 5) synthesis and 6) confirmation. Subsequently, changing times and the environment opened up opportunities for scholars to discuss the role of creative skills in problem solving. In 1995, Osborn integrated this creative skills process in solving problems involving five stages, namely 1) facts-finding, 2) problem-finding, 3) Ideal-finding, 4) solution-finding and 5), acceptance-finding. The five stages in the creative problem solving process are an attempt to connect two thoughts namely divergent and convergent. Divergent thinking is fundamental in enhancing the ability for individuals to think covergently (Isaksen et al., 1993; Ramachandran et al., 2011). To understand the term, it is best to understand the meaning of the word. Divergent is a mind-set that helps to generate variety of ideas to solve problems while convergent thinking focuses on evaluation, identification and focus on the purpose of generating ideas to provide next steps.

From this discussion, this paper takes into account the two concepts introduced by Osborn (1963) and Isaksen et al., (1993). This is because both principles have placed a direct emphasis on the problem-solving process and embodied the principles of creativity in solving problems. In addition, most researchers incorporated the principles of Creative Problem Solving (CPS) from Osborn (1963) and Isaksen et al. (1993) in their studies on the relevance of an issue or a problem.

Abraham Carmeli et al., (2013) stated that the Creative problem Solving Skills (CPS) process emphasized the principle that each individual has a creativity that is inherited and can be expressed by each student on different levels of thinking and age. In addition, creativity is reflected in interest, thinking and personal choice. In addition, creativity can be enhanced at every level of individual development. Thus, creative problem-solving thinking affects the ability to make decisions, constantly enhancing ideas and self-efficacy and increasing productivity (Adam et al., 2009). Emphasis on these skills is very crucial in producing high quality graduates who are competitive and have high potential in innovation.

\section{Factors Influencing Creative Problem Solving Skills}

Creative Problem Solving (CPS) is a cognitive process in finding ideas and al- 
ternative way to overcome any deficiency or barrier. Problem solving is closely related to the skills, comprehension and existing knowledege to solve problems in different situations. Various factors drive the process for creative problem solving skills. Creative solutions among students become a learning requirement both formal and informal settings. In order to fulfill the concept of creativity itself a number of factors need to be taken into account when developing competent individuals to solve a problem.

In National Education Blueprint (Higher Education) 2015 emphasized the element of knowledge for developing well being. From extensive knowledge in any field can develop creative individuals (Alane Jordon, 2010). There are many studies that emphasize knowledge in creative problem solving, thus encouraging students to understand and use information to identify suitable techniques and processes used in developing creative problem solving skills. (Zhiqiang Zhu et al., 2011; Yahya Buntat \& Noor Sharliana 2011; Yu-Shan Chang, 2013). Thus, it is proven true that knowledge of creative problem solving is a key element that can open up a space for students to generate creative thinking.

Besides that, collaborative knowledge sharing with other individuals able to produce high impact alternatives. In other words, creative problem solving skills that involve individuals as a group provide a stimulus that can release thoughts to be more creative. Treffinger \& Isaken, S. G. (2005) stated that knowledge sharing refers to the activity of transimitting knowledge from individual to other individual. In addition, it will make individuals more creative (Weisberg, 2006; Yu-Shan Chang, 2013). Based on the context of learning and teaching in a lecture, group discussion (cooperative learning) definitely can enhance the variety of ways or alternatives to solve a problem. In other words, lecturers encourage group involvement in problem solving to generate more creative thinking among students. Studies conducted on high school students showed that cooperative learning promotes interaction and thus stimulates students' ability to be more creative (Sternberg \& Lubart, 2004). From these discussions, it is clear that knowledge sharing can influence students to come up with strategies for solving a problem.

Creative problem solving also involves the teaching style of lecturers in the lecture, lecturers who provide encouragement through two-way interaction can have an impact on students. Shallcross (1981) stated that lecturers are not only limited to a single strategy and problem-solving method. This is because exposure to a variety of methods can stimulate students' desire to be more creative in solving problems and motivated them to learn (Cheng Kai Wen, 2011; Frenando Sousa et al., 2013). Therefore, teaching strategies must involve a process of reasoning that encourages students to think through critical questions and appropriate assignments.

Weisberg (2006) stated that the best way to help students think creatively is to start teaching and learning with questions based on the desired syllabus. In addition, stimulating materials and resources related to teaching and learning in the 
classroom can generate students' creative thinking (David Peterson et al., 2013; Mumford et. al, 2000). In other words, these resources should encourage students to be creative in dealing with an issue and boost their thinking level. Marke et al., (2008) stated that students should be given time to have better understanding of the learning materials provided in order to generate creative thinking. Kanbay et al. (2013) a creative person is capable of boosting their curiosity as more ideas are generated and new things are discovered. Thus, the desire to know something motivates individuals to build knowledge with a variety of methods and strategies to generate creative thinking. Therefore, good teaching resources and the perfect time can stimulate students' thinking to be more creative. In short, interesting teaching strategies and two-way interactions between lecturers and students have driven them to be more creative in solving particular problems in their learning.

Creative Problem Solving (CPS) is the relation between problem solving skills and creativity (Hosseini \& Watt 2010; Osborn, 1963). The connection between creativity and problem solving skills requires a supportive and encouraging environment. An unfavorable environment can lead to negative perceptions (Sternberg \& Lubart, 2004). Studies showed that the environment has a significant relationship with creativity (Yahya Buntat et al. 2011). Students will feel comfortable being creative when the university is in harmony. In the context of this discussion, the environment or press refers to the university environment that involves formal and informal learning. This process requires student interaction that involves the relationship between intra-university and inter-university that can provide maximum force to creative problem solving skills. This paper explores the concept of student engagement at the university which refers to the involvement of students in the university through association and organization activities and in the learning curriculum. University student engagement gives students an opportunity to explore informal and formal problem solving skills (Abraham et al., 2013; Yu-Shan Chang, 2013).

Meanwhile the concept of interuniversity promotes student engagement through other universities. This means that students not only get exposure in their own university but also get involved in other universities. This brings meaningful meaning to students' knowledge to prepare themselves in their thinking needs. Through attachment and networking between universities can create something more innovative and dynamic. This is because, exposure from other universities provides space and opportunities for students to compare and contrast the knowledge and knowledge gained, thus enabling more creative thinking.

Furthermore, the emphasis on informal education also contributes significantly to the creative problem-solving process. The informal education of university students takes into account their involvement in volunteering, community development programs and more. Through the combination of these environments it helps the cognitive to function effectively in creative problem 
solving skills. Thus, in order to cultivate creative ideas, it requires an environment that stimulates students' thinking to think creatively

\section{Conclusion}

As conclusion, students that practice creative level of solving have a quality working culture. This is because, with the emergence of quality graduates in various fields, employers will be interested in accepting them as they believe that students who have the creative ability to solve a problem can produce a good quality of work. Therefore, in general, the level of creativity that is common among public university students needs to be taken seriously to produce students with high levels of creativity (Ramachandran et al., 2011).

Basically, if new ideas made by an individual are rejected or unnoticed, this will cause the individual to lose confidence in his or her ability to enhance creativity (Torrance, 1993; Torrance \& Presbury, 1984). According to Fernando Sousa et al. (2013), individuals have the potential to increase their creativity in solving problems if they are engaged in the process of thinking development and do not give up on ideas or suggestions and continually carry out research without fail. As such, this paper is expected to assist lecturers, Malaysian public universities, the Ministry of Higher Education and other relevant parties to plan an effort to raise the level of student creativity especially before they leave the university. Thus, this strong cooperation not only reduces the rate of student dropout but also proves that graduates from local universities have a high degree of employability compared to other international universities.

\section{Acknowledgements}

This research is funded by research grant member PP-FPEND 2019.

\section{Conflicts of Interest}

The authors declare no conflicts of interest regarding the publication of this paper.

\section{References}

Abraham, C., Zachary, S., Galy, B., Tali, S., \& Roni, R. (2013). Transformational Leadership and Creative Problem Solving: The Mediating Role of Psychological Safety and Reflexivity. Journal of Creative Behavior, 48, 155-135. https://doi.org/10.1002/jocb.43

Adams, J. P., Kaczmarczyk, S., Picton, P., \& Demian, P. (2009). Problem Solving and Creativity in Engineering Perceptions of Novice and Professionals. In Proceedings of the World Congress on Engineering and Computer Science (Vol. I, pp. 1-6). San Francisco, CA.

Al Jughaiman, A., \& Mowrer-Reyolds, E. (2005). Teacher's Conception of Creativity and Creative Students. The Journal of Creative Behaviours, 39, 17-34. https://doi.org/10.1002/j.2162-6057.2005.tb01247.x

Alane, J. (2010). Creativity in the Classroom. New York: Routledge.

Barutcu, C. (2017). The Relationship between Problem Solving and Creative Thinking 
Skills among Nursing Students. International Journal of Psychology and Educational Studies, 4, 34-41.

Batıgün, A. D., \& Atay, A. (2014). Stress Factors among University Students: A Study on Interpersonal Relationship Style and Problem Solving Abilities (In Turkish). Hacettepe University Journal of Education, 29, 69-80.

Chang, Y. S. (2013). Student Technological Creativity Using Online Problem Solving Activities. International Journal of Technology and Design Education, 23, 803-816. https://doi.org/10.1007/s10798-012-9217-5

Cheng, K. W. (2011). When Creative Problem Solving Strategy Meet Web Based Cooperative Learning Environment in Accounting Education. New Horizons in Education, 59, 106-118.

David, P., Jamie, D. B., Kimberly, S. H. et al. (2013). Teaching People to Manage Constraints: Effects on Creative Problem Solving. Creativity Research Journal, 25, 335-347.

Dolgun, G., \& Erdoğan, S. (2012). Creative and Critical Thinking in Interpreting Nursing Research Findings (In Turkish). Journal of Anatolia Nursing and Health Sciences, 15, 223-230.

Elaheh, S., \& Barjoyai, B. (2012). Students Creative Potential in Higher Education Institutions; A Case Study in Malaysia Public Universities. International Journal of Fundamental Psychology \& Social Sciences, 2, 45.

Fernando, S., Ileana, M., Andre, W., \& Jado, P. (2013). Learning from Failure: A Case Study on Creative Problem Solving. Procedia-Social and Behavioral Sciences, 75, 570-580. https://doi.org/10.1016/j.sbspro.2013.04.062

Halizah, A., \& Ishak, R. (2008). Creative Thinking Skill Approach through Problem Based Learning: Pedagogy and Practice in the Engineering Classroom. International Journal of Human Social Sciences, 2, 334-339.

Hu, R., Su, X. H., \& Shieh, C. (2017). A Study on the Application of Creative Problem Solving Teaching to Statistics Teaching. Eurasia Journal of Mathematics, Science and Technology Education, 13, 3139-3149.

Isaksen, S. G., Puccio, G. J., \& Treffinger, D. J. (1993). An Ecological Approach to Creativity Research: Profiling For Creative Problem Solving. Journal of Creative Behaviour, 27, 149-170. https://doi.org/10.1002/j.2162-6057.1993.tb00704.x

Kanbay, Y., Aslan, Ö., Işık, E., \& Kılıç, N. (2013). Problem Solving and Critical Thinking Skills of Undergraduate Nursing Students (In Turkish). Journal of Higher Education and Science, 3, 244-251.

Leisian, S., \& Tatiana, P. (2015). Training Program on Creative Program at Russian Universities. Procedia-Social and Behavioral Science, 191, 2710-2715. https://doi.org/10.1016/j.sbspro.2015.04.388

Marke, C. J., Jo, S., \& Muammar, O. M. (2008). Development of Creativity. Learning and Individual Differences, 18, 402-417. https://doi.org/10.1016/j.lindif.2008.03.003

Mumford, M. D., Marks, M. A., Connelly, M. S., Zaccaro, S. J., \& Reiter-Palmon, R. (2000). Development of Leadership Skills: Experience and Timing. Leadership Quarterly, 11, 87-114. https://doi.org/10.1016/S1048-9843(99)00044-2

Osborn, A. F. (1963). Applied Imagination: Principles and Procedures of Creative Problem Solving (3rd Revised ed.). New York: Scribners.

Ramachandran, S. D., Chong, S. C., \& Ismail, H. (2011). Organisational Culture: An Exploratory Study Comparing Faculties 'Perspectives within Public and Private Universities in Malaysia. International Journal of Educational Management, 25, 615-634.

https://doi.org/10.1108/09513541111159086 
Ruhizan, Y., \& Shairah, Y. (2014). A Meta-Analysis Study on the Effectiveness of Creativity Approaches in Technology and Engineering Education. Asian Social Science, 10, 242-252. https://doi.org/10.5539/ass.v10n3p242

Saeidah, B., \& Nooreen, N. (2013). Investigating Relationship between Creativity and Academic Achievement of Malaysia Undergraduates. Jurnal Teknologi Malaysia, 65, 101-107.

Shallcross, D. J. (1981). Creative Thinking. Englewood Cliffs, NJ: Prentice Hall.

Sri, S., \& Jailani, Y. (2013). Tahap Kreativiti dalam kalangan Pelajar Politeknik Metro, Politeknik Premier dan Politeknik Konvensional di Malaysia (pp. 212-234). International Conference on Management Proceeding.

Sternberg, R. J., \& Lubart, W. M. (2004). How to Develop Students Creativity. Association for Supervision and Curriculum Development.

Torrance, E. P. (1993). Understanding Creativity: Where to Start? Psychological Inquiry, 14, 232-234. https://doi.org/10.1207/s15327965pli0403 17

Torrance, E. P., \& Presbury, J. (1984). The Criteria of Success Used in 242 Recent Experimental Studies of Creativity. Creative Child \& Adult Quarterly, 9, 238-242.

Tsemg, K. H., Chang, C. C., Lou, S. J., \& Hsu, P. S. (2013). Using Creative Problem Solving to Promote Students' Performance of Concept Mapping. International Journal of Technology and Design Education, 23, 1093-1109.

https://doi.org/10.1007/s10798-012-9230-8

Weisberg, R. W. (2006). Expertise and Reason in Creative Thinking: Evidence. From Case Studies and the Laboratory. In Creativity and Cognitive Development (pp. 7-42). New York: Cambridge University Press. https://doi.org/10.1017/CBO9780511606915.003

Yahaya, B., \& Noor, S. (2011). Faktor-faktor yang Mendorong Kreativiti di Kalangan Pelajar, Universiti Teknologi Malaysia. Journal of Educational Psychology and Counseling, 2, 175-208.

Zhu, Z. Q., Nagalingam, S., \& Hsu, H. Y. (2011). Towards a Creative Problem Solving Methodology with Knowledge Provision. 